\title{
Dictionary Look-up Strategies Used by Saudi EFL Students: A Think-Aloud Study
}

\author{
Eid Alhaisoni ${ }^{1}$ \\ ${ }^{1}$ Department of English, University of Hail, Saudi Arabia \\ Correspondence: Eid Alhaisoni, Department of English, University of Hail, Saudi Arabia. E-mail: \\ eid.alhaisoni@gmail.com
}

Received: February 2, 2020 Accepted: March 10, 2020 Online Published: March 21, 2020

doi:10.5539/ijel.v10n3p159 URL: https://doi.org/10.5539/ijel.v10n3p159

\begin{abstract}
This study investigates dictionary look-up strategies (DLS) while performing a reading task by 10 Saudi EFL English major students. Think-aloud protocol was used as an instrument in this study. The results revealed that the subjects used 31 DLS while reading. Reading L1 equivalents and reading L2 definitions were found to be the most frequent strategies that Saudi students use when referring to their dictionaries. The results also demonstrated that the students use the guessing strategy infrequently and prefer to resort to the dictionary immediately. The data also illustrated that the monolingual dictionary yielded different overall success rates. The users of the monolingual dictionary referred to their dictionary to solve 32 words problems (12.5\% of all look-ups).
\end{abstract}

Keywords: dictionary look-up strategies, think-aloud, EFL, strategies

\section{Introduction}

The importance of English as an international language has resulted in the rapid rise of dictionaries over the past decades. This boom reflects the tremendous need and demand for learners' dictionaries in English as a foreign language (EFL) and English as a second language (ESL) learning settings. Dictionaries are considered by many EFL learners as useful and helpful in learning English, and dictionary use is fairly common and probably necessary in language learning (Huang, 2003). Dictionaries are among the most successful and significant books about languages. They play a vital role not only in native language acquisition but also in foreign language learning (Li, 1998). The process of foreign language learning usually involves considerable use of dictionaries. Furthermore, dictionaries of different types have long been indispensable tools in language use for various purposes (e.g., reading, writing, and translating) (Violet, 2003). Dictionaries are useful not only to foreign learners, but also to non-native teachers of the language in coping with their teaching and marking needs. Even native speakers use them to find good examples and check collocations (Alhaisoni, 2008, 2016).

In the last few decades, there has emerged an interest in dictionary users. Research has been conducted to examine their needs for consulting dictionaries but this research is still limited especially in areas like look-up strategies where the detailed look-up process has not been investigated in dictionary research. Investigating users' interaction with dictionaries is essential because their comments and problems shed light on how dictionaries can be better designed and more effectively adapted for language use as well as providing valuable information to teachers.

In this study, we will investigate in detail the process of dictionary look-up strategies (DLS) using a think-aloud protocol method.

\section{Literature Review}

The study of dictionary use is most closely associated with reading because there is insufficient time to consult a dictionary when speaking and listening and teaching dictionary use for writing is less common than for reading (Tono, 2001). So, we find that many studies that investigated dictionary use relied on dictionary use while reading rather than other activities. Hence, we will mainly shed light on the investigation of dictionary strategies that L2 learners use to get the meaning of unfamiliar words while reading. It should be noted here that different studies ended up with different lists of strategies.

The first detailed study of procedures adopted by EFL learners when using dictionaries was conducted by Neubach and Cohen (1988). They used oral think-aloud reports and post-task interviews to investigate the search strategies and problems encountered. The subjects were six students at the pre-academic centre of the Hebrew University of 
Jerusalem. Two students each were selected from high-, intermediate- and low-level EFL classes. Each student was required to complete two tasks individually and each task required using a dictionary. The study found that students tended to read only the first definition and failed to read beyond that in a long entry. The participants also tried to gather information about the new word from context before looking it up; no one used a dictionary directly without regard for context and we expect our subjects to do the same. In addition, only the more advanced students seemed to benefit from dictionary use. These students formed semantic field expectations before they looked words up, and they used the dictionary only to deepen this understanding.

Another study was conducted on university students, similar to our subjects, by Bareggi (1989) through direct observation. In our study, we did not observe the students as we noticed that they were not happy to be observed. The findings of the study showed, as Neubach and Cohen found, that the students were unable to use contextual clues to locate the appropriate sense in polysemous entries of their monolingual dictionaries. Students like Neubach and Cohen's subjects have the tendency to adopt the strategy of retrieving the first sense. So, students do not go through all the definitions that are available in an entry. Scholfield (1982) gave the example of a learner who wanted to look up the word 'bracelets' after reading the sentence "'You needn't put the bracelets on,' said the inspector as the thief was led away" (p. 193). The Oxford Advanced Learner's Dictionary has the definition 'ornamental band worn on the wrist or arm'. Scholfield argued that the error some learners may make is to take this definition without trying to understand where there is any metaphorical or pragmatic knowledge involved. Hence, they may not look up other definitions.

Tono (1984) proposed a study to investigate the reference skills of 402 Japanese students at Tokyo Gakugei University, of whom 63 were English majors. They were asked to translate English passages from American magazines into Japanese using eight different sets of bilingual dictionaries. Seven different pieces of information were selected to see if the subjects used them properly: grammatical information, verb patterns, countable vs. uncountable nouns, glosses, collocations, idioms, and run-ons. The study found that these users tended to choose the first definition of an entry. Only if the information in the dictionary indicated the inappropriacy of the first definition did they move to the next one. When the second one was also inadequate, they moved to the third one and so forth. Tono argued that this was the case when the given information was properly used. On the other hand, when the subjects did not use the given information, they just chose the first definition. The subjects seemed not to read whole entries but would rather stop searching for the required meaning as soon as possible.

Blachowicz et al. (1990) found that their fourth-grade students used this strategy of choosing the first listed sense in a translation task. He also found that some of his students did not fit the chosen dictionary meaning into the context. The data were collected by means of observation, interview, and test. The results of the study indicated that the students used different skills for looking up the target words. The students seemed to adopt the strategy of formulating a possible word meaning before starting the look-up (see Alseweed, 2000; Al-Fuhaid, 2004; Almuzainy, 2005; Alhaisoni, 2008). When locating the headword, the students either adopted the skill of plodding through each entry letter page by page or ignored it. They found that the students also used one of the following strategies:

1) As found by Tono (1984) mentioned above, they searched for a meaning that seemed to fit the target sentence and stopped as soon as their criteria were met without looking past the definition they chose (in some cases, they stopped after reading the first definition).

2) They read through each and all definitions then went back to choose the one thought to have the best fit.

3) They read all the definitions but proceeded to formulate their own definitions which encompassed all the definitions, looking for something in common among the definitions.

Nesi and Meara (1994) asked adults learners to compose sentences with unfamiliar words they had looked up in monolingual dictionaries. Their subjects were 51 Portuguese undergraduates studying English at tertiary level in Portugal and 44 Malaysian undergraduates studying English at tertiary level in Malaysia. Both groups of subjects were studying in education faculties and intended to become English teachers, similar to our subjects who are English major students. But in our study, the students will be asked to read an English text, not to compose, as we anticipate that the dictionary will be reported to be used frequently in reading in Saudi Arabia. By examining the errors in these sentences, Nesi and Meara found that almost a quarter were caused by 'Kidrule'. This strategy means that users pick a familiar word from the entry and insert it in the text.

Mullich (1990) found the same strategy amongst his senior high school subjects who were asked to translate a text from French or English into German. He also found that his subjects took notice only of the first meaning in dictionary entries of polysemous words.

Huang (2003) conducted a study to find out dictionary use strategies among Chinese university English major 
students. Her subjects reported using various dictionary strategies while reading. One of the most frequent strategies was selecting one most suitable sense when a word had several meanings rather than picking one randomly without differentiation in order to understand the text they were reading. She found that $95 \%$ of her subjects claimed to use this strategy. Furthermore, the results showed that highly proficient students were able to read, understand, and choose the most suitable sense to fit the context according to what they reported in the questionnaire. Additionally, $86 \%$ of the subjects claimed to copy the Chinese glosses of the word into the margins of the English passage they were reading whereas copying English glosses was less frequently done.

As it can be noticed from the above findings, reading only the first sense was found in most of the studies reviewed above. Moreover, the studies reviewed above have come up with different strategies and used different instruments in order to find out such strategies.

\section{Methods}

\subsection{Subjects}

The subjects who participated in this study were 10 Saudi EFL English major students in their final year at the university. The reason behind targeting final year students is because they have been exposed to the English language at the college for a minimum of four years and they have therefore gained experience in using language learning strategies, including dictionary look-up strategies.

Their age ranged between 22 and 25 years old. Their native language is Arabic. They were selected randomly, subject to willingness to participate in the current study.

\subsection{Instruments}

In this study, think-aloud was used. Think-aloud is an innovative and powerful research tool developed and widely used in the field of psychology (Ericsson \& Simon, 1980). It has proved to be one of the introspective methods used as an insightful and valuable method for studying learners' processing of knowledge (Ericsson \& Simon, 1984, 1993). In a think-aloud report, the participant verbalises while completing the task. The subject is asked to voice their thoughts, feelings, and opinions during the task. Ericsson and Simon argued that there are two main memories, the short-term memory and the long-term memory. The most recently processed information is stored temporarily in the short-term memory, which can be accessed directly through the subjects' think-aloud process. Readers, for example, would find no difficulty in verbalising their thoughts, which would help the researcher to record their processes. Ericsson and Simon, however, cautioned that there should be no interference from the researcher; otherwise, it would affect the data. In the long-term memory, information is stored and can be accessed indirectly through the short-term memory.

This method is used frequently in single-user performance evaluations. The data can be collected by means of tape recording, video recording or specially designed written forms. The use of this protocol in the field of psychology and social science has a long history, but it has only recently been introduced into research related to second/foreign language and learning use (McDonough, 1995). It has been used in the field of learning strategies by many researchers such as Hosenfeld (1977), Van Parreren and Schouten-Van Parreren (1981), Ahmed (1989), and Anderson (1991). In the area of dictionary use, research by Ard (1982), Neubach and Cohen (1988), Wingate (2002), and Thumb (2004) are examples of think-aloud studies whose aim were to access directly the reference strategies of particular dictionary user groups.

\subsection{Reading Text}

We decided to target DLS during a reading task because "Reading is the dominant activity" (Cowie, 1999, p. 185) for which dictionaries are consulted. Many studies have found that reading is the most common activity during which dictionaries are used. Care was taken to choose a text that was linguistically somewhat demanding but not too difficult. Hence, we decided to use a general text which we judged to be familiar in content for the students of this study. The text is about society in Islam. Students in Saudi Arabia are familiar with such texts as they study many Islamic texts in intermediate and high school.

In order to check the readability of the text, we ran two readability tests. The readability formulas, called the Flesch Reading Ease and the Flesch-Kincaid Grade Level, are designed to indicate how difficult a reading passage is to understand using limited information from the superficial form of the text. Although they use similar information, the results of the two tests do not always correlate (a text with a better score on the Flesch Reading Ease test over another text may end up with a worse score on the Flesch-Kincaid Grade Level test). In the Flesch Reading Ease test, higher scores indicate material that is easier to read; lower numbers mark harder-to-read passages. As a rule of thumb, scores of 90-100 are considered easily understandable by an average fifth grader. Eighth- and ninth-grade students could easily understand passages with a score of 60-70, and passages with results of $0-30$ are best understood by university 
graduates. In this study, we aimed to have a somewhat demanding text as we wanted students to refer to their dictionaries so we could investigate the DLS used. The test results are shown in Table 1 below.

Table 1. Flesch and Flesch-Kincaid readability test results

\begin{tabular}{ll}
\hline Count & \\
\hline Words & 360 \\
Characters & 1757 \\
Paragraphs & 7 \\
Sentences & 24 \\
Average & \\
Sentences per paragraph & 4 \\
Words per sentence & 15 \\
Characters per word & 4.6 \\
Readability & \\
Passive sentences & $12 \%$ \\
Flesch Reading Ease & 41.5 \\
Flesch-Kincaid Grade Level & 11.1 \\
\hline
\end{tabular}

In order to assess vocabulary level in greater detail, we used a lexical frequency profile (http://www.lextutor.ca/vp). This is a computer program that takes any text and divides its words into four categories by frequency: (1) the most frequent 1000 words of English, (2) the second most frequent thousand words of English, i.e., 1001 to 2000, (3) the academic words of English (the AWL, 570 words that are frequent in academic texts across subjects), and (4) the remainder which are not found on the other lists. In other words, VP measures the proportions of low- and high-frequency vocabulary used by a native speaker or language learner in a written text.

Table 2. Vocabulary level in the reading text used in this study

\begin{tabular}{lllll}
\hline & Families & Types & Tokens & Percent \\
\hline K1 words (1 to 1000) & $\mathbf{8 3}$ & $\mathbf{9 4}$ & $\mathbf{2 7 8}$ & $\mathbf{7 6 . 8 0 \%}$ \\
Function & ---------- & --------- & 196 & $54.14 \%$ \\
Content & & & 82 & $22.65 \%$ \\
Anglo-Sax & ---------- & ------- & 31 & $8.56 \%$ \\
K2 words (1001 to 2000) & 9 & 10 & 15 & $4.14 \%$ \\
Anglo-Sax & & & 3 & $0.83 \%$ \\
K1 + K2 & & & & $80.94 \%$ \\
AWL words (academic) & 22 & 24 & 43 & $11.88 \%$ \\
Off-list words & -------- & 22 & 26 & $7.18 \%$ \\
Total & 114 & 150 & 362 & $100 \%$ \\
\hline
\end{tabular}

The output for our text, as shown in Table 2, shows that the percentage of $\mathrm{K} 1+\mathrm{K} 2$ words is about $80.94 \%$, while the percentage of words from the AWL is $11.88 \%$. Off-list words, which may include proper nouns, unusual words, specialist vocabulary, acronyms, abbreviations, and misspellings, comprise slightly fewer words, contributing $7.18 \%$ to the total. The off-list words in this text are the following 22 words: Abrogate, Adam, Allah, brotherhood, citizenship, corrupt, disabled, entitled, Eve, genuine, harmoniously, harmony, humanity, inescapable, injustice, Islam, mindedness, prosperity, Quran, racial, solidarity, utmost. Obviously, three of these are culturally very familiar (Allah, Islam, Quran) and two others are proper names. The remainder were considered enough to prompt enough look-ups to give some data without making the text too hard. It should be mentioned here that 18 words of these off-list words $(81.81 \%)$ were looked up by our subjects.

\subsection{Transcription and Coding}

Kasper (1998) argued that researchers have two options when they want to choose a coding scheme - either choose an existing one or design a new one. Before settling on the second option, we went through previous studies in order to examine carefully the available coding schemes for their suitability to our study. Unfortunately, we found that look-up behaviour studies have not yet attempted to analyse and describe their data in a systemic way except Thumb (2004) who created her own coding scheme in order to classify the look-up strategies of Chinese students. However, we did not choose this coding because it was not clear enough how she created her scheme. So, it was necessary to create our own coding scheme based on our own data. It should be mentioned here that we referred to the previous 
studies and strategies identified as a guide when searching and extracting strategies from our own data.

To categorise the strategies, we wrote down all the coded strategies on different cards. Thirty-eight strategies were identified. Later, we began going through the coded strategies by asking a contrast question: "Is this a strategy and if it is, is it different from the others?" Consequently, 31 strategies emerged. Moreover, we went through these strategies many times in order to classify them into different logical groups and we recognised that they can be classified into six groups based on the stages and sequence of the search. The main categories recognised were pre-search strategies, entry-search strategies, internal search (within entry) strategies, information-checking strategies, cross-referencing strategies, and post-search strategies.

\section{Discussion}

The results reveal that the total frequency for all the strategies utilised by the 10 subjects is 1272 with an average of 127.2 strategy tokens for each subject and 4.96 strategy tokens per look-up. The total tokens used by subjects range from 17 to 283. For example, Subject 1 used strategy tokens more than anybody else. His raw frequencies score for all the strategies he used is 283 . His most frequently used strategies were reading L1 equivalents (94 times, 33.2\%) followed by using the bilingualised dictionary (43 times, $15.19 \%$ ).

\subsection{The Seven Most Frequently Used DLS}

Table 3. The seven most frequently used DLS

\begin{tabular}{llll}
\hline DLS & Order & Mean \% & SD \\
\hline Reading L1 equivalents & 1 & 27.58 & 12.31 \\
Reading L2 definitions & 2 & 10.73 & 10.08 \\
Alphabetical search & 3 & 9.85 & 7.93 \\
Referring to bilingual CD-ROM dictionary & 4 & 8.95 & 8.45 \\
Scan all senses and homonyms & 5 & 7.75 & 3.77 \\
Writing down Arabic glosses in the margin & 6 & 7.36 & 10.30 \\
Referring to bilingualised dictionary & 7 & 4.44 & 8.08 \\
\hline
\end{tabular}

The results show that by far the most frequently used DLS is reading L1 equivalents or referring to Arabic equivalents (mean $27.58 \%$ and SD 12.31). Our result is significant according to the one-way repeated measures ANOVA $(\mathrm{F}=6.291, \mathrm{p}=.003)$. In order to know where the differences lie among these strategies, Bonferroni-adjusted multiple comparisons were performed. The result showed that the difference is between reading L1 equivalents on one hand and alphabetical search, scanning all senses, writing down Arabic glosses and referring to CD-ROM dictionary on the other hand. This result is consistent with Al-Jarf (1999) who found that her Saudi university students preferred getting an Arabic equivalent of an English word over any other DLS. Furthermore, Macintosh (1998) found that EFL students in the University of Ottawa consulted equivalents more frequently than other parts of dictionary entries. The reason seems to be that learners do not really 'know' a foreign lexical item until they can provide its L1 equivalent (Tomaszczyk, 1983, p. 46; see also Snell-Hornby, 1987, p. 159; Hartmann, 1994). Another reason might be, as Tomaszczyk (1983, p. 43) argued, that "some semantic and syntactic properties of words do not become apparent until one has confronted them with counterparts in other languages".

Secondly, reading L2 definitions ranks second (mean 10.73\% and SD 10.08). This result indicates that our subjects tend to refer to L2 definitions when resorting to their dictionaries but it is not significantly different from other strategies. Fan (2000) found that his Chinese students referred to L2 definitions but less frequently than referring to Chinese equivalents.

Alphabetical search is reported to be the third most frequently used strategy by Saudi learners (mean $9.85 \%$ and SD 7.93). Scholfield (1982) and other researchers consider alphabetical search to be one of the main steps in dictionary search. This is right in the case of print dictionary but with electronic dictionaries, learners do not need such a strategy. Holzman (2000) argued that the dictionary search processes are likely to be similar for both books and electronic dictionaries. The difference is that the search in print dictionaries requires knowledge of the order of the alphabet. On the other hand, electronic dictionary search requires knowledge of the basic functions of the machine.

Accessing the bilingual CD-ROM dictionary is reported to be the fourth most frequently used strategy by the subjects of the present study. This agrees with the results of previous studies (e.g., Tomaszczyk, 1979; Ahmed, 1988; Atkins \& Knowles, 1990; Alqahtani, 2005).

Scanning all senses and homonyms is one of the most commonly used strategies by Saudi EFL undergraduate students, ranking fifth among the strategies found to be used by our subjects (mean $7.75 \%$ and SD 3.77). This result 
indicates that the subjects tend to read all the senses available in a dictionary entry. Thumb (2004) found that her Chinese students scanned all the senses available in their bilingualised dictionaries.

Writing down Arabic glosses is the sixth most commonly used strategy (mean 7.36\% and SD 10.30). This result concurs with Almuzainy (2005) who found that this strategy was used by his Saudi ESL subjects frequently. Furthermore, this is consistent with Huang (2003) who found that a great majority of the participants (86\%) always or often, when checking out meanings of an English word in a dictionary, copied the Chinese glosses of the word in the margins of the English passage they were reading.

\subsection{The Seven Least Frequently Used DLS}

Table 4. The seven least frequently used DLS

\begin{tabular}{llll}
\hline DLS & Order & Mean & SD \\
\hline Rereading L2 definition & 1 & .070 & .222 \\
Formulating strategy & 2 & .070 & .222 \\
Reading examples & 3 & .078 & .2470 \\
Referring to bilingual paper dictionary & 4 & .087 & .2763 \\
Searching for synonym & 4 & .156 & .494 \\
Guessing after using dictionary & 5 & .176 & .446 \\
Moving to another dictionary to confirm what was understood from previous look-up & 6 & .260 & .669 \\
\hline
\end{tabular}

Regarding the seven least used strategies, Table 4 shows that four of the strategies are internal search strategies and three strategies belong to three different categories (pre-search strategies, cross-referencing strategies and post-search strategies). The results show that rereading an L2 definition is the least frequently used of all these strategies among learners. We found through the analysis of the students' protocols that they tend to read the L2 definition once and then either get the meaning, move to another dictionary, or skip it. In our point of view, this strategy might help the dictionary user if he tries to reread the definition several times as he might be able to get the meaning of unknown words or he might guess the meaning of the unknown words that might arise in the definition and this could help him to get the right meaning. The students who used this strategy were able to get the appropriate meaning of an unfamiliar word. The results also indicate that one of the least used internal search strategies is the formulating strategy, ranked second here (mean .070 and SD .222). We recognised through analysis of the protocols that when the students failed to understand the L2 definition, they rarely tried to paraphrase it in the L2. The most common solution was either skipping it or moving on to another dictionary. Reading examples is also reported as one of the least used strategies, ranking third. Al-Jarf (1999) also found that only 12\% of her Saudi students read examples. This might be due to the fact that the students are unaware of the importance of examples provided in the dictionary (see Winkler, 2003).

Another infrequent dictionary internal search strategy is searching for a synonym. This ranks fifth (mean .156 and SD .494). This agrees with Alqahtani (2005), who found that his Saudi students infrequently referred to their dictionary to check a synonym. Moreover, Winkler (2003) found that synonyms are infrequently looked up in the dictionary. But this contradicts with El-Badry's (1990) results, who found that $73 \%$ of her subjects referred to their dictionaries to find out the synonyms of a word. Moreover, Tomaszczyk (1979) found that $74 \%$ of his subjects used their dictionaries for checking synonyms. The reason might be that referring to a synonym in the dictionary is connected with types of task the learners do. Clearly, the students might need synonyms when they write more than when they read.

Referring to a bilingual paper dictionary is found to be one of the least used dictionary strategies by Saudi EFL students, ranking fourth with a mean percentage use .087 and SD .2763 . The result appears to be consistent with Winkler's (2003) results where he found that his subjects referred to a CD-ROM dictionary more than a print dictionary in a writing task.

Guessing the meaning of an unknown word after using the dictionary is also one of the seven least used dictionary strategies, ranking sixth (mean .176 and SD .446). The analysis of think-aloud protocols showed that the subjects of the current study guessed the unfamiliar word in the text infrequently even before resorting to the dictionary. Alseweed (2000) found that guessing was not the first option of his Saudi undergraduate English major students who consulted the dictionary more frequently than other strategies. The reason seems to be that the students lacked the skill of guessing and were in need of training on how to use this strategy.

Finally, moving to another dictionary to confirm what was understood from a previous look-up is ranked seventh of 
the least used dictionary strategies. This indicates that our subjects do not tend to search in another dictionary to confirm what they understood from the previous look-up. It should be mentioned here that cross-referencing strategies are reported as infrequently used by our subjects.

In the next section, we look at the frequency of use of DLS by Saudi EFL undergraduate English major students obtained from the analysis of the think-aloud protocols.

\subsection{Frequency of DLS}

The aim of this section is to describe differences in strategy use within each DLS category. So, we arranged in order of frequency the strategies belonging to each category. We willvl start with the pre-entry search strategies.

\subsubsection{Pre-Entry Search Strategies}

The main objective of this section is to find out the most and least used pre-search strategies that Saudi EFL undergraduate English majors use. This category is divided into two groups: the choice of the dictionary, which consists of five strategies, and word preparation, which consists of two strategies.

Table 5. Summary of the use of pre-search strategies by the subjects

\begin{tabular}{llll}
\hline Pre-search strategies & \multicolumn{2}{l}{ Descriptive statistics } \\
\cline { 3 - 4 } & & \multicolumn{2}{l}{ Mean of individual percentage scores } \\
\cline { 3 - 4 } & & Mean & SD \\
\hline Dictionary choice strategies & Referring to bilingual paper dictionary & .087 & .276 \\
& Referring to monolingual dictionary & 4.34 & 6.87 \\
& Referring to bilingualised dictionary & 4.44 & 8.08 \\
& Referring to bilingual CD-ROM dictionary & 8.95 & 8.45 \\
& Referring to HHE dictionary & 2.10 & 6.67 \\
Word preparation strategies & Strip inflection & .70 & .664 \\
& Identifying the compound word, phrase or idiom & .45 & .638 \\
\hline
\end{tabular}

Referring to bilingual CD-ROM dictionaries emerged as the most frequently used pre-search strategies (mean 8.95 and SD 8.45$)(42.43 \%)$. Our result is marginally significant according to one-way repeated measures ANOVA ( $\mathrm{F}=$ $2.662, \mathrm{p}=.072$ ). In fact, this DLS was ranked fourth in the seven most used DLS by our subjects. It is apparent that our subjects rely heavily on the bilingual dictionary when they decide to consult a dictionary. This concurs with the findings of the previous studies (c.f., Tomaszczyk, 1979; Atkins \& Knowles, 1990; Al-Ajmi, 1992; Schmitt, 1997; Al-Jarf, 1999; Lew, 2004; Alqahtani, 2005).

Moreover, referring to bilingualised dictionaries is reported to be the second most used DLS by Saudi students (mean 4.44 and SD 8.08) (31.51\%). The preference for bilingualised dictionaries might be due to the fact that the subjects use them as bilingual dictionaries, so they refer to L1 equivalents rather than L2 definitions. See Laufer and Kimmel (1997) and Fan (2000).

The third most common strategy is referring to monolingual dictionaries (mean 4.43 and SD 6.87 ) at $12.60 \%$. More frequent use of a bilingual dictionary is likely to result in less frequent use of a monolingual dictionary. Consulting a monolingual dictionary is the strategy least used by Saudi EFL learners in Al-Fuhaid's study (2004) and Alqahtani's study (2005). The popularity of the bilingual dictionary and the infrequent use of the monolingual, however, do not apply to all the subjects as three subjects (i.e., Alsesy, Hamza, and Alaraby) preferred using the monolingual dictionary in dealing with vocabulary problems. The main criticism against monolingual dictionaries is that one encounters more unknown words in the definitions. Moreover, it has been found through the analysis of think-aloud protocols that some of the informants failed to benefit from the monolingual dictionary as they had difficulty understanding the definition provided by such reference material. Al-Fuhaid (2004) reported that his students praised bilingual dictionaries for saving time and providing clearer concepts.

Hand held electronic dictionaries (HHE) are used infrequently by Saudi students (mean 2.10 and SD 6.67) (10\%). It should be noted here that in the think-aloud session, only one student used an HHE dictionary. He did not use any other types of dictionary despite failing many times to find the word sought and to get the right meaning when he reached the correct entry. He said after the think-aloud session that he was used to using this kind of dictionary and he was not familiar with print or CD-ROM ones.

With respect to word preparation strategies, two strategies were identified. They were both used infrequently. Strip inflection was used infrequently but slightly more than identifying the compound words, phrase or idiom (mean .70 
and SD .664). Identifying the compound words, phrase or idiom was a little-used strategy. There was only one compound word and only four students $(40 \%)$ recognised it and tried to break it down whereas six $(60 \%)$ of the subjects did not recognise this and tried to search for it in the dictionary as one word and under one entry. The following excerpt illustrates two cases where the first one recognised the compound word whereas the latter did not.

In this way the individual works with a sound social-mindedness. 'Social-mindedness' — "This word I do not know. It is a very strange word. I am not sure if I will find it in E-E-A dictionary or not... oh, not there. Okay, let me search under 'mind'... oh, this is 'mind'." IN THE DICTIONARY, 'MIND' HAS TWO ENTRIES, ONE AS A NOUN AND ONE AS VERB. HE READ ALL THE EQUIVALENTS INCLUDED UNDER THE TWO ENTRIES. "Okay, I know 'social' and 'mind' now but how can I put them together... a really difficult word... let me try to guess it." In this way the individual works with a sound social-mindedness, In this way the individual works with a sound social-mindedness, In this way the individual works with a sound social-mindedness. "Really I do not know."

It is apparent that the student recognised that this is a compound word and broke it down but could not get the right meaning, subsequently ignoring it without trying to use cross-referencing strategies. Wingate (2004) found that her students made 27 attempts to find compound nouns and only five (18.5\%) were successful. She argued that the main reason for failure was that learners tried to look up the compounds as a whole and did not find an entry.

In this way the individual works with a sound social-mindedness. "There is a word I do not know, which is 'social-mindedness'. Let me refer to the CD-ROM dictionary." IT IS A BILINGUAL ONE. "I did not find it. What is going on? How come it is not in the dictionary? Well, I might find it in the E-E-A dictionary. Oh, my God, it is not here as well. Okay, let me move on."

The example above shows that the student did not recognise that this word is a compound and he tried to find it as one word. When he failed to find it in the first dictionary, he used the cross-referencing strategy by moving on to a different dictionary, but he could not find it there either and then decided to ignore it. It is clear that the students did not try to break it down or use another strategy such as the guessing strategy to solve the problem.

\subsubsection{Entry-Search Strategies}

Table 6. Summary of the use of entry-search strategies by the subjects

\begin{tabular}{|c|c|c|}
\hline \multirow[t]{3}{*}{ Entry-search strategies } & \multicolumn{2}{|c|}{ Descriptive statistics } \\
\hline & \multicolumn{2}{|c|}{ Mean of individual percentage scores } \\
\hline & Mean & SD \\
\hline Alphabetical search & 9.85 & 7.93 \\
\hline Looking up each main element of a compound, phrase or idiom & .454 & .638 \\
\hline
\end{tabular}

When it comes to entry-search strategies, two strategies were spotted from the subjects' protocols. These two strategies are alphabetical search and looking up each main element of a compound word, phrase or idiom. As discussed earlier (5.71), alphabetical search is reported to be among the seven most used dictionary strategies by Saudi learners, ranking third. It is one of the main skills that dictionary users use when they are searching in a print dictionary. On the other hand, finding each main element of a compound word, phrase or idiom, which is obviously dependent on the occurrence of such words in the text, is a strategy infrequently used by our subjects. There was only one compound word in the text and, as mentioned earlier, only $40 \%$ of the subjects recognised it and tried to break it down and search under different entries. Our result seems to be consistent with Mackintosh (1995), who found that all her subjects had problems identifying terminological units and breaking down lengthy noun phrases into smaller units. She argued that "they often expected to find dictionary entries for very long noun phrases. Even if they did manage to break them down and find entries for their component parts, they had difficulty stringing them together" (Mackintosh, 1995, p. 181). 


\subsubsection{Internal Search Strategies}

Table 7. Internal search strategies used by the subjects

\begin{tabular}{|c|c|c|c|}
\hline \multirow[t]{3}{*}{ Internal search strategies } & & \multicolumn{2}{|c|}{ Descriptive statistics } \\
\hline & & \multicolumn{2}{|c|}{ Mean of individual percentage scores } \\
\hline & & Mean & SD \\
\hline \multirow[t]{3}{*}{ Choosing sense strategies } & Scan all senses or homonyms & 7.75 & 3.77 \\
\hline & Fall back on the first sense & 1.12 & 2.01 \\
\hline & Termination strategy & 2.25 & 2.94 \\
\hline \multirow{7}{*}{$\begin{array}{l}\text { Reading information about the } \\
\text { chosen sense strategies }\end{array}$} & Searching for synonym & .156 & .494 \\
\hline & Reading definitions & 10.73 & 10.08 \\
\hline & Reading equivalents & 27.58 & 12.31 \\
\hline & Checking pronunciation & .567 & 1.04 \\
\hline & Rereading definition & .070 & .222 \\
\hline & Referring to examples & .078 & .247 \\
\hline & Formulation strategy & .070 & .222 \\
\hline
\end{tabular}

This subcategory comprises internal search strategies within entries that Saudi students use when they resort to their dictionaries. These 10 strategies are divided into two groups. The first one is related to choosing a sense while the latter is related to reading information about the chosen sense.

With regard to choosing a sense strategy, the results show that scanning all senses and homonyms is the most used strategy among the three strategies (mean 7.75 and SD 3.77) and the fifth most used strategy among all the dictionary strategies found through the analysis of the think-aloud protocols. Garcia (2006) conducted a study investigating lexical strategies in L1 and L2 writing. He found that scanning all the translations/definitions before selecting the right sense is a common dictionary strategy among Mexican EFL university students. Scanning all the senses was one of seven steps that ESL students had to take for proficient dictionary use to aid English reading comprehension, as discussed in detail by Scholfield (1982) in a non-empirical study. Later in 1999, he reduced these steps to five. Underhill (1980) argued that dictionary users should scan all of the definitions in the entry before deciding which is the right one. The following example, taken from Alsesy's protocols, illustrates this case:

The unity of humanity is not only in its origin but also in its ultimate aims. According to Islam, the final goal of humanity is God. From Him we come, for Him we live and to Him we shall all return. In fact, the sole purpose of creation as described by the Qur'an is to worship God and serve His cause, the cause of truth and justice, of love and mercy, of brotherhood and morality.

"Well, I understand it but there is a word that I think has a different meaning to the one I know... I think it ('cause') means في سبيله HE GUESSED IT CORRECTLY.

1) Cause, a person, event or thing that makes something happen. "This does fit the context."

2) A fact that makes it right or reasonable for you to feel or behave in a particular way. "This does fit the context."

3) An organisation, belief or aim that a group of people support or fight for. "This is close to what I am thinking of."

4) To join with other people or group to oppose an enemy. "No, this is not related; it is far away."

5) A case that is brought to a court of law.

"Well, so the third definition is what I was thinking of." في سبيلة

HE GOT THE RIGHT MEANING.

It is apparent that Alsesy was able to guess the meaning before resorting to the dictionary, but he referred to the dictionary and found various senses and read all of them before deciding which one to choose. He was successful.

The termination strategy is found to be used by the subjects of this study but infrequently (mean 2.25, SD 2.94). This takes place when the dictionary user decides to stop searching as he gets what he thinks is the right meaning and decides to not read the rest of the senses. This was found by Thumb (2004) to be a common strategy among her Chinese university students. A striking example of this can be found in Alsesy's protocol:

The role of individual is complementary to that of society. 'Complementary'-“Well, let me refer to the 
dictionary." Complementary things go well together although they are usually different. "Oh, that was what I thought of." HE DID NOT READ THE REST OF THE SENSES.

It is clear that Alsesy read only the first sense and then stopped as he recognised that he had got the right meaning. It should be mentioned here that this word has three senses. This indicates that the student examined the context of unknown words sufficiently well before resorting to the dictionary. This definitely helped him to get the right meaning without reading all the senses.

With regard to strategies related to reading information about the chosen sense, we can report that reading L1 equivalents is the strategy most frequently used by the subjects of this study and the result is significant according to one-way repeated measures ANOVA $(\mathrm{F}=25.230, \mathrm{p}=.001)$. The Bonferroni-adjusted multiple comparisons were made to check for significant differences. The results showed that reading L1 equivalents is significantly different from all strategies related to reading information about the chosen sense except reading L2 definitions. Moreover, it ranked first among the seven most used DLS. This result appears to be consistent with what Mackintosh (1995) found among her ESL students and with Laufer and Kimmel (1997). Reading L2 definitions, in turn, is used more often than the other strategies but the difference is not significant. This is the second most used strategies among dictionary strategies. Scholfield (1999) argued that the information provided in bilingual dictionaries is always shorter and easier to understand as it is in the native language. However, it is also argued that equivalents always deceive because they are rarely perfect translation equivalent (Scholfield, 1995).

Rereading L2 definitions and the formulation strategy are reported to be the least used of strategies related to reading information about the chosen sense (mean .070 and SD .222). Indeed, overall, these two are among the least used dictionary strategies that Saudi EFL students use when they resort to their dictionaries while reading an English text. The infrequent use of reformulation is in line with Thumb (2004) who found that her Chinese university students used this strategy infrequently. The reason for using this strategy is to make a chosen definition substitutable for a target word (Thumb, 2004, p. 87). According to Scholfield (1982, p. 190), the need for adjustments arises from the fact that a dictionary paraphrase or synonym definition, though comprehensible in itself, is often not straightforwardly substitutable for the item being defined. The use of this strategy also suggests that the learners have understood the dictionary definition. Let us examine the following excerpt that was taken from Alsesy's protocols:

In return he is entitled to security and care. 'He is entitled' - 'I do not know what 'entitled' means; I will check it in the monolingual dictionary."

To give someone the official right to do or have something. To be entitled.

If a book, play, etc. is entitled, to be entitled. HE READ ALL SENSES.

In return he is entitled to security and care. "Yes, it means he is in charge of or responsible for security and care." Should he become disabled, disabled. HE WAS SUCCESSFUL.

The excerpt above demonstrates that Alsesy referred to a monolingual dictionary to get the meaning of 'entitle', reading all the senses available. Then he read the sentence again trying to see which definition fits the context. He was able to formulate/paraphrase the definition by using his own words and he was successful. This indicates that the student rightfully thought he had understood the definition. Furthermore, it demonstrates that he has good vocabulary knowledge.

\subsubsection{Information-Checking Strategies}

Table 8. Information-checking strategies used by the subjects

\begin{tabular}{lll}
\hline Information-checking strategies & \multicolumn{2}{l}{ Descriptive statistics } \\
\cline { 2 - 3 } & \multicolumn{2}{l}{ Mean of individual percentage scores } \\
\cline { 2 - 3 } & Mean\% & SD \\
\hline Fitting the meaning to the context & 3.18 & 2.76 \\
Checking the meaning against what was previously guessed before look-up & 2.13 & 2.58 \\
Checking the meaning against what was found in a previous look-up of the same word & .368 & .671 \\
Checking the meaning against uncertain retrieved knowledge of the word before look- up & .514 & .735 \\
Checking the meaning by translating the word into L1 & .901 & 1.91 \\
\hline
\end{tabular}

Table 8 shows that the analysis of think-aloud protocols revealed five different strategies of checking information found in the dictionary, but it should be noted here that these strategies were infrequently used compared with other DLS. This might indicate that our subjects do not pay much attention to checking the meaning obtained from the 
dictionary, assuming the information they had to be the right one. To the best of our knowledge, checking the meaning against what was found in a previous look-up of the same word, checking the meaning against uncertain retrieved knowledge of the word before look-up, and checking the meaning by translating the word into L1 are strategies not found in the previous studies. They are a new contribution. The most used information-checking strategy is fitting the meaning to the context. This strategy takes place when the dictionary user finds the meaning of an unknown word and then tries to match it with the context to see if it fits or not. This strategy came first (mean 3.18 and SD 2.78) but the results indicate that it is not a common strategy among our subjects as only $17.5 \%$ of the total look-ups (256) were matched with context. This result echoes the findings of Thumb (2004) who found that her subjects rarely fitted the meaning they got from the dictionary to the context. This finding also appears to be in line with Blachowicz et al.'s (1990) result, which found that some students did not fit the chosen dictionary meaning in the context sentence (p. 10). They thought that their students did not use this strategy because they were "schema directed" (ibid, p. 10). If the dictionary user found that the dictionary meaning was the meaning he conceived before undertaking the look-up task, he would bypass the 'fit in the context sentence' aspect (Thumb, 2004, p. 86). In his study of Saudi university students, Al-Smael (2000) found that one of the main inefficient uses of the dictionary is readily accepting unsuitable dictionary information without checking its contextual appropriateness. In this study, we found some cases supporting this vein as shown in Alsesy's example:

The unity of humanity is not only in its origin but also in its ultimate aims. 'Ultimate' - "Well, this is the first time I am seeing this word written but I have heard it before and I think it means the best; let me check it in an E-E dictionary." The best or modern example of something. "Oh, that is what I expected."

It is noticeable that this subject knew one of the meanings of the word before he resorted to the dictionary. When he referred to his monolingual dictionary, he found the meaning he already conceived. He did not read the rest of the senses and terminated the search, although he did not match what he found in the dictionary with the context. It is essential that teachers at school and university teach their students how they can match what they find in the dictionary with text they are reading.

The second most used information-checking strategy is checking the meaning against what was previously guessed before look-up (mean 2.13 and SD 2.58). This result is parallel to what other researchers (Neubach \& Cohen, 1988; Blachowicz et al., 1990; Diab \& Hamdan, 1999) have found.

On the other hand, checking the meaning against what was found in a previous look-up of the same word is the least used strategy in this category by our subjects. This result is expected since the students resorted to one dictionary 256 times and they only referred 12 times to another dictionary. Moreover, checking the meaning against uncertain retrieved knowledge of the word before look-up was used infrequently by the subjects of this study (mean .514 and SD.73). It should be noted here that those with greater vocabulary knowledge used this strategy significantly more that those with low vocabulary knowledge $\left(\mathrm{r}=.697^{*}, \mathrm{p}=.025\right)$. This indicates that highly proficient students are keen to know the meaning of the word sought.

\subsubsection{Cross-Referencing Strategies}

Table 9. Cross-referencing strategies used by the subjects

\begin{tabular}{lll}
\hline Cross-referencing strategies & \multicolumn{2}{l}{ Descriptive statistics } \\
\cline { 2 - 3 } & \multicolumn{2}{l}{ Mean of individual percentage scores } \\
\cline { 2 - 3 } & Mean\% & SD \\
\hline Moving to another dictionary due to failure to find the word & .563 & .854 \\
Moving to another dictionary due to failure to get the right meaning & .395 & .762 \\
Moving to another dictionary in order to confirm what was understood from previous & .260 & .669 \\
look-up of the same word & & \\
\hline
\end{tabular}

Table 9 shows the cross-referencing strategies used by the Saudi students when reading an English text. Overall, this category is reported to be the least used category by the subjects. This indicates that our subjects do not refer to another dictionary frequently). As mentioned above, the students referred 12 out of 256 times to another dictionary. Through the analysis of the think-aloud protocols, we recognised that the students usually skip a word when they cannot get the right meaning. The explanation for this unwillingness may be that the subjects feel that a second search is time consuming. They may also lack training in cross-referencing skills and awareness of the importance of cross-referencing as a dictionary strategy (Garcia, 2006, p. 219). In his study on lexical strategies used by Mexican students, Garcia (2006) found that out of all instances of problem-solving strategies that involved dictionary use, only nine included cross-referencing of some type (either within the same reference book or in a different book). 
The students used three different cross-referencing strategies. The most used strategy was moving to another dictionary due to a failure to find the word with mean .563 and SD.854, followed by moving to another dictionary due to failure to get the right meaning (mean .395 and SD .762), and finally moving to another dictionary in order to confirm what was understood from previous look-up of the same word (mean .260 and SD .669). The following three examples taken from the subjects' protocols illustrate the above three strategies:

In this way the individual works with a sound social-mindedness and genuine feeling of inescapable responsibility. It is his role to do the utmost for his society and contribute to its common welfare. "I do not know the meaning of the word 'inescapable'; let's refer to an E-A CD-ROM dictionary. Oh, it is not there... Okay, let me refer to an E-E-A dictionary. It is a good dictionary... Oh, I got it, good. It means مفر منه (unavoidable)." CORRECT.

The above example illustrates that for this problem, cross-referencing was helpful and the student was able to get the right meaning. However, this does not mean that cross-referencing is always helpful. This is very clear in the following example, where cross-referencing did not help the student who referred to the second dictionary to confirm his understanding of the previous look-up, as he did not find the word in the second dictionary and then tried to guess it.

"Another word is 'inescapable'; I do not know it."

PAUSE SEARCHING. "Ens, ens, escapable - oh, that it is."

An inescapable fact or situation is one that you cannot avoid or ignore. "I think it means المسئولية الحتمية in Arabic." HE GOT IT CORRECT. THERE IS ONLY ONE SENSE IN THE MONOLINGUAL DICTIONARY. "But I will check it in the E-A dictionary also... Mmm. It is not in the bilingual dictionary. Very strange." HE DID NOT FIND THE ENTRY. "I do not like bilingual dictionaries. They are bad dictionaries but sometimes you should refer to them." "Let me guess from the definition of L2. I think it is المسئوليات الحتمية." HE GOT IT.

\section{Between the two there are social solidarity and mutual responsibility.}

"Well, 'solidarity' and 'mutual', I do not know their meanings; let me check 'solidarity' first in the E-E dictionary.". Solidarity means loyalty and general agreement between all the people in a group or between different groups because they all have a shared aim. IT HAS ONLY ONE SENSE. "Let me read the explanation again" - means loyalty and general agreement between all the people in a group or between different groups because they all have a shared aim. "Let me read it again" - means loyalty and general agreement between all the people in a group or between different groups because they all have a shared aim. UNSUCCESSFUL. HE FAILED TO UNDERSTAND THE L2 DEFINITION.

"Well, I am not sure about the meaning." HE WAS NOT SUCCESSFUL. "Let me refer to the E-A CD-ROM dictionary to check it better" - تكافل وتماسك. THERE ARE ONLY TWO SENSES IN THE BILINGUAL DICTIONARY. THEY ARE ALIKE AND THEY ARE CORRECT, SO HE GOT THE RIGHT MEANING. SUCCESSFUL.

"Let me read the sentence again"-Between the two there are social solidarity and mutual responsibility. "Well, it is clear now. Let me check."

The above excerpt clarifies the cross-referencing strategy that the student used. Because he could not understand the definition offered by the monolingual dictionary, he referred to the bilingual CD-ROM dictionary. This was helpful and he got the meaning.

4.3.6 Post-Search Strategies

Table 10. Post-search strategies used by the subjects

\begin{tabular}{lll}
\hline \multirow{2}{*}{ Post-search strategies } & \multicolumn{2}{l}{ Descriptive statistics } \\
\cline { 2 - 3 } & \multicolumn{2}{l}{ Mean of individual percentage scores } \\
\cline { 2 - 3 } & Mean\% & SD \\
\hline Guessing after using dictionary & .176 & .446 \\
Writing down Arabic glosses & 7.36 & 10.30 \\
Writing down English glosses & .555 & 1.75 \\
Skipping & 1.65 & 1.86 \\
\hline
\end{tabular}


The analysis of the think-aloud protocols revealed that our subjects use four different post-search strategies. Writing down Arabic glosses in the margin ranks as the most used strategy of the four (mean 7.36 and SD 10.30). Furthermore, this strategy is ranked sixth among the seven most used DLS by Saudi students. More importantly, this strategy is also reported to be among the most used dictionary strategies found by Huang (2003). She found that $86 \%$ of her Chinese students checked out the meaning of an English word from a dictionary and then copied the Chinese glosses of the word in the margins of the English passage they were reading. Moreover, our result appears to be consistent with Almuzainy's (2005) results. This demonstrates an interest in retaining vocabulary as students see reading as a source of new words to learn.

By contrast, writing down the English glosses is reported to the least used post-search strategy by the subjects of this study. Moreover, it concurs with Huang (2003) and Almuzainy (2005), whose subjects claimed that they rarely used this strategy. This might be because students like to learn meanings in L1 and not in L2.

Skipping words is reported to be the second most used post-search strategy (mean 1.56 and SD 1.86). Almuzainy (2005) found this strategy to be one of the least used dictionary strategies by Saudi students. This result reveals that the majority of the subjects prefer to check every unknown word (Hosenfeld, 1979). Moreover, it is probable that our subjects, as EFL learners majoring in English, feel that they need to continue to build up their vocabulary store to cope with the variety of texts to which they are exposed. It is quite obvious that those with lower vocabulary knowledge use this strategy significantly more than those with greater vocabulary knowledge. The reason seems to be that high-proficiency learners are able to use different strategies to reach the meaning, not only resorting to the dictionary. Al-Fuhaid (2004) found that his high-proficiency students tended to be unwilling to skip any new word.

\section{Model of Dictionary Use in Reception}

Different researchers have adopted different models of dictionary use. Some of these models were not based on empirical studies but on the researchers' experiences (i.e., Scholfield, 1982, 1999; Hartmann, 1989, 2001; Bogaards, 1995; Nation, 2001). On the other hand, there were some researchers who adopted models based on empirical studies (i.e., Mullich, 1990; Miller \& Gildea, 1985; Nesi, 1999).

Taking into account the comments and criticism that the above models received and based on the findings of the current study, a tentative model of the DLS while reading by Saudi EFL university students is proposed (see Figure 1). This model aims to present the dictionary look-up process of the Saudi students when performing a reading task with the help of the dictionary. This model consists of five obligatory strategies each with multiple strategies. These obligatory steps are the reading process, selecting a dictionary, guessing or skipping, entry search, and internal search/reading of information. The model also consists of five optional steps. This means it is possible to proceed to the next step without performing the optional one, either because the word does not need it or the person chooses to skip it. These steps are gathering prior information about problem item, preparing word/phrase for look-up, checking against prior information, cross-referencing, and post-search. Moreover, our model consists of four boxes that do not contain strategies but rather a point where a decision needs to be made (yes/no). These boxes are: identifying vocabulary problem, finding a matching headword, finding a sense/homonym that seems right, and either checking information or not. 


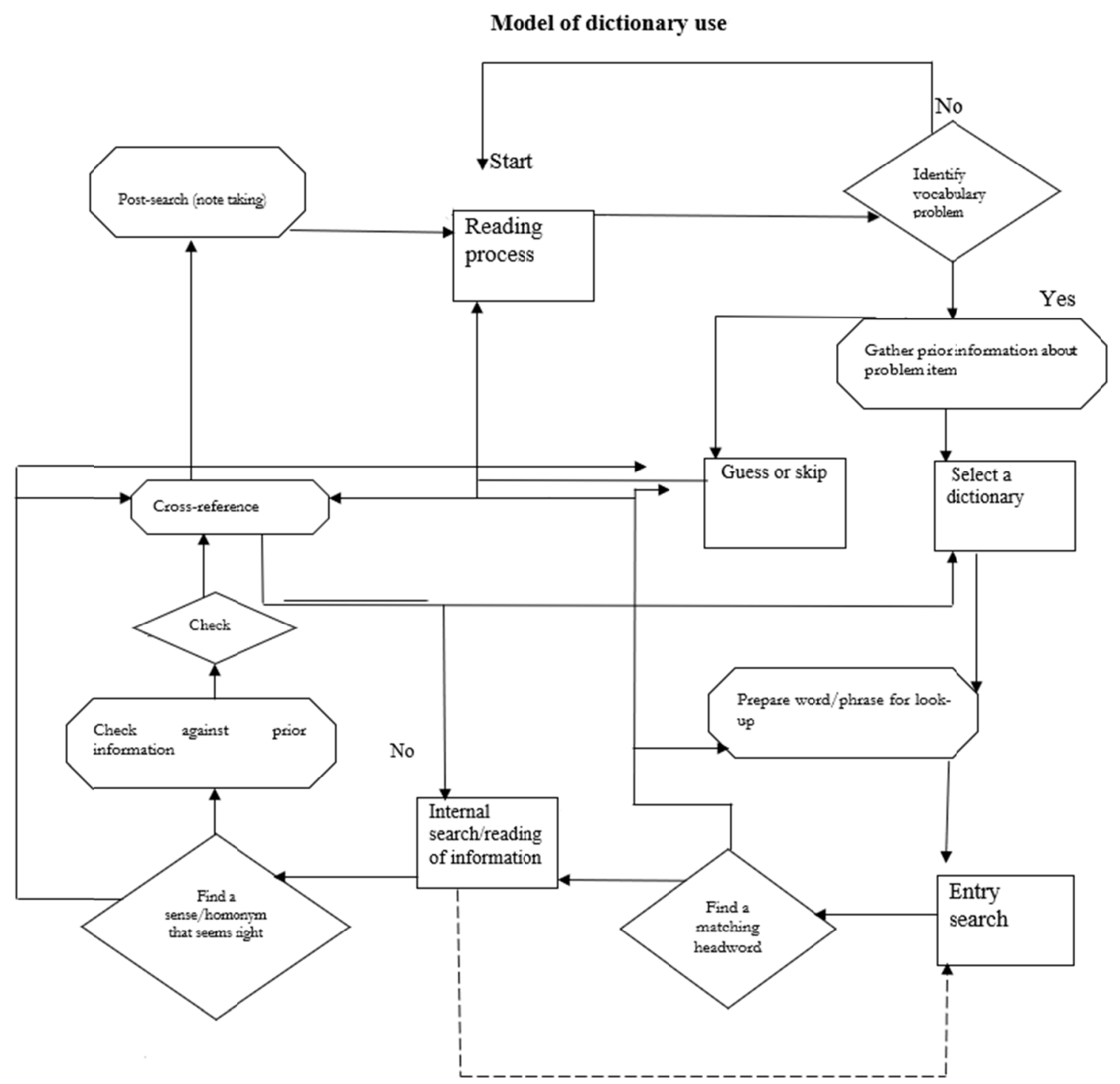

Figure 1. Model of dictionary use

\section{Conclusion}

This study investigated DLS while performing a reading task by 10 Saudi EFL English major students. The results revealed that the CD-ROM E-A bilingual dictionary is used more frequently than other types of dictionary but the difference is not significant. The data also showed that the consultation of the monolingual dictionary, though vastly less frequent, was a more successful problem-solving strategy than checking other types of dictionary by a small percentage: $78 \%$ vs. $73 \%$ for the E-A dictionary. All DLS where L1 is involved, such as asking for the Arabic meaning, using a bilingual dictionary, writing down the Arabic glosses, and reading L1 equivalents, were reported to be highly popular among our subjects. The results also showed that reading Arabic equivalents and English definitions are reported to be the most used DLS among our subjects. Moreover, the results revealed that subjects of this study tend to not read the L2 definition more than once and then either get it or skip without trying to reread it in order to comprehend the meaning. The findings depicted that our subjects were not always aware of the optimum way of using dictionaries. The results also showed that the subjects resorted to their dictionary mainly for searching for the meaning of a totally unknown lexical item. Researchers such as Scholfield (1982), Miller and Gildea (1985), Schelbert (1988), and Hartmann (1991) have argued that look-up strategy use is complex, but this has not been supported by empirical evidence. The present study has confirmed this claim through producing clear empirical evidence. The think-aloud data revealed that the students used a variety of strategies with varied frequency connected together in a complex way. 


\section{References}

Ahmad, M. (1988). Vocabulary learning strategies: A case study of Sudanese learners of English. Unpublished PhD thesis. University College of North Wales Bangor.

Al-Ajmi, H. (1992). The use of monolingual English and bilingual Arabic-English dictionaries in Kuwait: an experimental investigation into the dictionary used and reference skills deployed by university of arts and science. Unpublished $\mathrm{PhD}$ Thesis, University of Leeds.

Al-Ajmi, H. (2002). Which microstructure features of bilingual dictionaries affect users' look-up performance. International Journal of Lexicography, 15(2), 119-131. https://doi.org/10.1093/ijl/15.2.119

Al-Fuhaid, M. (2004). Vocabulary learning strategies: an empirical study of their use and evaluation by Saudi EFL learners majoring in English. Unpublished $\mathrm{PhD}$ thesis, University of Durham.

Al-Jarf, R. (1999). Use of electronic dictionaries in ESL classroom (Vol. IV). TESOL Arabia' 99. 5th Annual Conference entitled "Teaching, learning and technology". Conference Proceedings.

Al-Smael, F. (2000). A think-aloud protocols investigation of lexico-semantic problems and problem-solving strategies among trainee English-Arabic translators (BL). Unpublished $\mathrm{PhD}$ thesis. University of Durham.

Alhaisoni, E. (2008). The Use of Dictionaries by Saudi EFL Students Across Educational Level and University Major. Unpublished $\mathrm{PhD}$ thesis, University of Essex

Alhaisoni, E. (2016). EFL Teachers' and Students' Perceptions of Dictionary Use and Preferences. International Journal of Linguistics, 8(6), 31-52. https://doi.org/10.5296/ijl.v8i6.10267

Almuzainy, S. (2005). Dictionary use strategies by Saudi L2 learners. Unpublished MA dissertation. University of Essex.

Alqahtani, M. (2005). The use of vocabulary learning strategies by EFL learners at three different educational levels. Unpublished PhD thesis, University of Essex.

Alseweed, M. (1996). Word-solving strategies of Saudi EFL readers. Unpublished MA dissertation. University of Essex.

Alseweed, M. (2000). The effect of proficiency and training on word-solving strategies of Arab EFL readers. Unpublished $\mathrm{PhD}$ thesis. University of Essex.

Anderson, J. (1983). The architecture of cognition. Cambridge, MA: Harvard University Press.

Anderson, N. (1991). Individual differences in strategy use in second language reading and resting. The Modern Language Journal, 75(4), 469-472. https://doi.org/10.1111/j.1540-4781.1991.tb05384.x

Ard, J. (1982). The use of bilingual dictionaries by ESL students while writing. ITL, Review of Applied Linguistics, $58,1-27$. https://doi.org/10.1075/itl.58.01ard

Atkins, B., \& Knowles, F. (1990). Interim report on the EURALEX/AILA Research Project into dictionary use. In I. Magay \& J. Zigany (Eds.), Buda LEX 88 proceedings (pp. 381-392). Budapest: Akadémiai Kiadó.

Bareggi, C. (1989). Students and the dictionary: an inquiry among students of English following a degree course in modern foreign languages ate the University of Turin. In Z. Prat (Ed.), Dal Dizionario ai Dizionari (pp. 155190). Turin: Terrenia Stampatori.

Blachowicz, C. et al. (1990). Observing dictionary users: teachers look at fourth grade students. Paper presented at the annual meeting of the American educational association. Boston.

Bogaards, P. (1993). Models of dictionary use. Toegepaste Taalwetenschap in Artikelen, 47-48, 17-28. https://doi.org/10.1075/ttwia.46-47.03bog

Bogaards, P., \& van der Kloot, W. A. (2001). The use of grammatical information in learners' dictionaries. International Journal of Lexicography, 14(2), 97-121. https://doi.org/10.1093/ijl/14.2.97

Cowie, A. (1981) The treatment of collocations and idioms in learners' dictionaries. Applied Linguistics, 2(3), $223-$ 235. https://doi.org/10.1093/applin/2.3.223

Cowie, A. (1987). The dictionary and the language learners. Tubingen: Niemeyer. https://doi.org/10.1515/9783111340500

Cowie, A. (1989). The language of examples in learners' dictionaries. In G. James (Ed.), Lexicographers and Their Works (vol. 14, pp. 55-65). 
Cowie, A. (1999). English dictionaries for foreign learners: A history. Oxford: Clarendon Press.

Diab, T., \& Hamdan, M. (1999). Interacting with words and dictionaries: The case of Jordanian EFL learners. International Journal of Lexicography, 12(4), 281-305. https://doi.org/10.1093/ijl/12.4.281

El-Badry, N. (1990). Bilingual dictionaries of English and Arabic for Arabic-speaking advanced learners of English. Unpublished $\mathrm{PhD}$ thesis, University of Exeter

Ericson, K., \& Simons, H. (1984/1993). Protocols analysis: verbal reports as data (revised ed.). Cambridge: MIT Press.

Fan, M. (2000). The dictionary look-up behaviour of Hong Kong students: A Large-scale survey. Educational Journal, 28(1), 123-138.

Garcia, S. (2006). Lexical strategies in L1 and L2 writing: a study with Mexican University EFL students. Unpublished PhD thesis. University of Essex

Hartmann, R. (1983). The bilingual learner's dictionary and its uses. Multilingua, 2(4), 195-201. https://doi.org/10.1515/mult.1983.2.4.195

Hartmann, R. (1987). Four perspectives in dictionary use: a critical view of research methods. In A. Cowie (Ed.), The dictionary and the language learner (pp. 11-28). Papers from the EURALEX seminar at the University of Leeds, 1-3 April 1985. Tübingen: Max Niemeyer Verlag.

Hartmann, R. (1989). Sociology of the dictionary users: hypotheses and empirical studies. In F. J. Hausmann et al. (Eds.), An international encyclopaedia of lexicography (1, pp. 102-111). Berlin: W. de Gruyter.

Hartmann, R. (1992). Lexicography, with particular reference to English learners' dictionary. Language Teaching, 25, 151-159. https://doi.org/10.1017/S02614444800006868

Hartmann, R. (1994). Bilingualized versions of learners' dictionaries. Fremdsprachen Lehren und Lernen, 23, 206 220.

Hartmann, R., \& James, G. (1998). Dictionary of lexicography. London, New York: Routledge. https://doi.org/10.4324/9780203159040

Harvey, K., \& Yuill, D. (1997). A study of the use of a monolingual pedagogical dictionary by learners of English engaged in writing. Applied Linguistics, 18(3), 253-278. https://doi.org/10.1093/applin/18.3.253

Holzman, S. (2000). Reading English as a foreign language with an electronic dictionary: an exploratory study of the processes of L2 classroom reading by $L 1$ Hebrew speaking college students in Israel. $\mathrm{PhD}$ dissertation. Indiana University of Pennsylvania.

Horsfall, P. (1997). Dictionary skills in MFL 11-16. Language Learning Journal, 15, 3-9. https://doi.org/10.1080/09571739785200021

Hosenfeld, C. (1977). A preliminary investigation of the reading strategies of proficient and non-successful second language learners. System, 5, 110-123. https://doi.org/10.1016/0346-251X(77)90087-2

Huang, D. (2003). Taiwanese university English majors' beliefs about English dictionaries and their dictionary strategy use. Unpublished $\mathrm{PhD}$, University of Texas at Austin

Hulstijn, J. (1993). When do foreign-language readers look up the meaning of unfamiliar words? the influence of task and learner variables. The Modern Language Journal, 77, 139-147. https://doi.org/10.1111/j.1540-4781.1993.tb01957.x

Hulstijn, J., \& Atkins, B. T. S. (1998). Empirical research on dictionary use in foreign- language learning: survey and discussion. In B. T. S. Atkins (Ed.), Using dictionaries: by language learners and translators. Tübingen: Max Niemeyer.

Hulstijn, J., Hollander, M., \& Greidanus, T. (1996). Incidental vocabulary learning by advanced foreign language students: the influence of marginal glosses, dictionary use, and reoccurrence of unknown words. The Modern Language Journal, 80(3), 327-339. https://doi.org/10.1111/j.1540-4781.1996.tb01614.x

Laufer, B. (2000). Dictionaries and vocabulary learning: Does technology make a difference? EURALEX, Stuttgart.

Laufer, B., Elder, C., Hill, K., \& Congdon, P. (2004). Size and strength: do we need both to Measure vocabulary knowledge? Language Testing, 2, 202-226. https://doi.org/10.1191/02655322041t277oa

Laufer, B., \& Hadar, L. (1997). Assessing the effectiveness of monolingual, bilingual, and "bilingualized" dictionaries in the comprehension and production of new words. The Modern Language Journal, 81(2), 189- 
196. https://doi.org/10.1111/j.1540-4781.1997.tb01174.x

Laufer, B., \& Hill, M. (2000). What lexical information do L2 learners select in a CALL dictionary and how does it affect word retention? Language Learning \& Technology, 3(2), 58-76.

Laufer, B., \& Kimmel, M. (1997). Bilingualized dictionaries: how learners really use them. System, 25(3), 361-369. https://doi.org/10.1016/S0346-251X(97)00028-6

Lew, R. (2002a). A study in the use of bilingual and monolingual dictionaries by Polish learners of English: A preliminary report. In A. Braasch \& C. Povlsen (Eds.), Proceedings of the 10th Euralex International Congress (pp. 759-763). EURALEX 2002, Copenhagen, Denmark. Copenhagen: Center for Sprogteknologi.

Lew, R. (2002b). Questionnaires in dictionary use research: A reexamination. In A. Braasch \& C. Povlsen (Eds.), Proceedings of the 10th Euralex International Congress (pp. 267-271). EURALEX 2002, Copenhagen, Denmark. Copenhagen: Center for Sprogteknologi.

Lew, R. (2004a). How do Polish learners of English rate bilingual and monolingual dictionaries? In G. Williams \& S. Vessier (Eds.), Proceedings of the Eleventh EURALEX International Congress (697-706). EURALEX 2004, Lorient, France. Lorient: Université De Bretagne Sud.

Lew, R. (2004b). Which dictionary for whom? Receptive use of bilingual, monolingual and semi-bilingual dictionaries by Polish learners of English (p. 217). Poznań: Motivex.

Lew, R., \& Dziemianko, A. (2006). A new type of folk-inspired definition in English monolingual learners' dictionaries and its usefulness for conveying syntactic information. International Journal of Lexicography, 19(3), 225-242. https://doi.org/10.1093/ijl/ec1011

Li, L. (1989). Extending vocabulary in English for specific purposes with special reference to Chinese university students. MPhil thesis. University of Exeter.

Li, L. (1998). A study of dictionary used by Chinese university learners of English for specific purposes. Unpublished $\mathrm{PhD}$ thesis. University of Exeter.

Mackintosh, K. (1995). An empirical study of dictionary used in version. Unpublished MA dissertation. University of Ottawa.

Mackintosh, K. (1998). An empirical study of dictionary used in L2-L1 translation. In B. T. S. Atkins (Ed.), Using dictionaries: studies of dictionary use by language learners and translators. Tübingen: Niemeyer.

Miller, G., \& Gildea, P. (1985). How to misread a dictionary. AILA Bulletin (final issue), 13-26.

Miller, G., \& Gildea, P. (1987). How children learn words. Scientific American, September, 86-91.

Mitchell, E. (1983). Search-do-reading: difficulties in using a dictionary. Aberdeen: College of Education.

Müllich, H. (1990). Die definition ist blöd. Herubersetzen mit dem einsprachigen Worterbuch. Das franzosische und englische lernerworterbuch in der Hand der deutschen Schuler. Tubingen: Max Niemeyer. https://doi.org/10.1515/9783111635644

Nation, I. S. P. (2001). Learning vocabulary in another language. Cambridge: Cambridge University Press. https://doi.org/10.1017/CBO9781139524759

Nation, P. (2003) The role of first language in foreign language learning. Asian EFL Journal, 5(2).

Nesi, H. (1994). The effect of language background and culture on productive dictionary use. In W. E. A. Martin (Ed.), EURALEX'94 (pp. 577-585). Amsterdam: New University.

Nesi, H. (1996). The role of illustrative examples in productive dictionary use. Dictionaries, 17, 198-206. https://doi.org/10.1353/dic.1996.0008

Nesi, H. (1999a). The specification of dictionary reference skills in Higher Education. In R. Hartmann (Ed.) Dictionaries in Language Learning (pp. 53-66). Recommendations, National Reports and Thematic Reports from the TNP Sub-Project 9: Dictionaries. Berlin: Free University Berlin.

Nesi, H. (1999b). A user's guide to electronic dictionaries for language learners. International Journal of Lexicography, 12(1), 55-66. https://doi.org/10.1093/ijl/12.1.55

Nesi, H. (2000). The use and abuse of EFL dictionaries. Tübingen: Max Niemeyer. https://doi.org/10.1515/9783110946031

Nesi, H., \& Haill, R. (2002) A study of dictionary use by international students at a British university. International Journal of Lexicography, 15(4), 277-306. https://doi.org/10.1093/ij1/15.4.277 
Nesi, H., \& Meara, P. (1994). Patterns of misrepresentation in the productive use of EFL dictionary definitions. System, 22(1). https://doi.org/10.1016/0346-251X(94)90036-1

Neubach, A., \& Cohen, A. D. (1988). Processing strategies and problems encountered in the use of dictionaries. Dictionaries, 10, 1-19. https://doi.org/10.1353/dic.1988.0018

Schmitt, N. (1997). Vocabulary learning strategies. In N. Schmitt \& M. McCathy (Eds.), Vocabulary: Description, acquisition and pedagogy (pp. 199-227). Cambridge: Cambridge University Press.

Scholfield, P. (1982a). The role of bilingual dictionaries in ESL/EFL: a positive view. RELC Guidelines, 4(1), 84-98.

Scholfield, P. (1982b). The role of bilingual dictionaries in ESL/EFL: A positive view. Guidelines, 4(1), 84-98.

Scholfield, P. (1987). Active and passive vocabulary: bilingual dictionaries' and teachers' judgments. Bangor Research Papers in Linguistics, 2, 18-26.

Schofield, P. (1999). Dictionary use in reception. International Journal of Lexicography, 12(1), 13-34. https://doi.org/10.1093/ijl/12.1.13

Thumb, Y. J. (2004). Dictionary look-up strategies and the bilingualised learner's dictionary: think-aloud study. Tübingen: Niemeyer. https://doi.org/10.1515/9783110918809

Tomaszczyk, J. (1979). Dictionaries: users and uses. Glottodidactica, 12, 103-119.

Tomaszczyk, J. (1981). Issues and development in bilingual pedagogical lexicography. Applied Linguistics, 2(3), 287-296. https://doi.org/10.1093/applin/II.3.287

Tomaszczyk, J. (1983). The case of bilingual dictionaries for foreign language learners. In R. R. K. Hartmann (Ed.), Lexicography: Principles and Practice (pp. 41-51, 289-297). London: Academic Press. Bingen: Niemeyer.

Tono, Y. (1984). On the dictionary user's reference skills. Bachelor of Education, Tokyo Gakugei University.

Tono, Y. (2001). Research on dictionary use in the context of foreign language learning: Focus on reading comprehension. Tübingen: Niemeyer. https://doi.org/10.1515/9783110915013

Underhill, A. (1985). Working with the monolingual learners' dictionary. In R. Ilson (Ed.), Dictionaries, lexicography, and language learning (pp. 103-114). Oxford: Pergamon Press.

Violet, K. M. (2003). The impact of dictionary used in four different conditions on incidental vocabulary learning. MA dissertation. Hong Kong University.

Wingate, U. (2004). Dictionary use - the need to teach strategies. Language learning Journal, 29(5), 11. https://doi.org/10.1080/09571730485200031

Winkler, B. (2001). Students working with an English learners' dictionary on CD-ROM. Paper presented in the ITMELT 2001 conference, the Hong Kong Polytechnic University, Hong Kong.

Winkler, B. (2003). The use of English learners' dictionaries in book and on CD-ROM. Unpublished $\mathrm{PhD}$ thesis, Open University.

\section{Copyrights}

Copyright for this article is retained by the author, with first publication rights granted to the journal.

This is an open-access article distributed under the terms and conditions of the Creative Commons Attribution license (http://creativecommons.org/licenses/by/4.0/). 